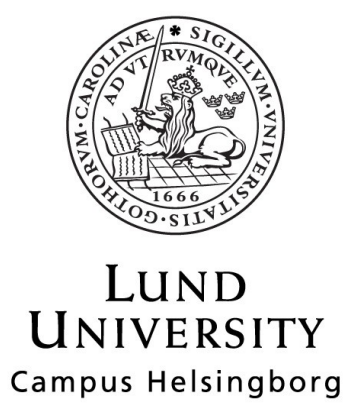

\title{
Design for Six Sigma and Lean Product Development - Differences, Similarities and Links -
}

\author{
Jean-Baptiste Fouquet, MSc \\ Ida Gremyr, Ph.D. Assistant Professor \\ At \\ Quality Sciences, Chalmers University, Göteborg, Sweden \\ jb.fouquet@gmail.com, ida.gremyr@chalmers.se
}

Keywords: DFSS, Lean, LPD, Product Development, Six Sigma

Category: Conceptual Paper

\section{Introduction}

This research began with the initiation of a general discussion between customers, suppliers and scholars concerning the way product development (PD) should be carried out to be most efficient and how a supplier can best respond to customers' expectations in PD. This strategic sector is under increasing pressure for efficiency since many companies have increased their production capability (Liker \& Morgan, 2006). Two methodologies have helped manufacturing to reach satisfactory levels of competitiveness: Six Sigma and Lean Manufacturing (Womack, Jones \& Roos, 1992, Harry \& Schroeder, 2000). Six Sigma is an improvement methodology that guides companies toward achieving a six-sigma level of capability and Lean Manufacturing is a philosophy that guides a company toward reducing the wastes in manufacturing and streamlining processes. Two sisters' initiatives have been created for PD needs: Lean Product Development (LPD) and Design for Six Sigma (DFSS) (Reinertsen, 2005, Gremyr, 2005). This paper explores the two methodologies and tries to give a comparison in order to fill the lack thereof that seems to exist in the literature and provide insight to academicians and practitioners to perhaps find a "hybrid" method.

\section{Method}

This paper is based on a qualitative study of selected literature and empirical data. The empirical data collected were provided by semi-structured interviews with practitioners in companies using the methodologies. Eight companies were chosen, four for each methodology. Each uses one of the methodologies.

The questionnaire used in the interviews is composed of open-ended questions. As the questions in a survey of this kind influence the results, it is important to know what kind of questions are asked. The twenty questions deal with the opinion of the interviewee about the methodology and its application and the implications of its use in the company. While the character of the questions enabled a broad range of answers, 
the small number of interviews does not permit a generalization of the findings, even though they give general view of the methodologies in the companies.

The respondents were practitioners trained in, or knowledgeable about the methodologies. They received their knowledge in training sessions or studies they made: some of them taught one of the methodologies. They work in firms using the methodologies: General Electric (GE), Volvo Aero, Volvo Car Corporation (VCC) and Siemens, which use DFSS and Scania, IVF, Bahco and Autoliv, which use LPD.

The literature chosen is mainly intended for managers of companies, who whish to gain knowledge of DFSS and LPD. This literature is primarily positive about the methodology described. This positivism required a double check of the reading in order to validate the findings reported (Bryman, 2004).

\section{Lean Product Development}

LPD is a methodology that attempts to apply the principles learned in Lean Manufacturing in the PD area. These are made to create a flow in PD that will help the PD process to go faster. This possibility to realize new product faster will enhance the reactivity of a company in the market (Reinertsen, 2005). Visualization tools, such as process mapping, show the improvement opportunities in the PD process and enable companies to make the PD process more fluent. Based on continuous improvement and visual communication, its goal is to enhance customers' values by developing top class quality products, increasing the quality from the start of a project (Liker \& Morgan, 2006). The use of a common platform appears to be a decisive factor for the realization of the methodology (Mascitelli, 2004) in term of reducing the price of development and insisting on specific innovations focused on customer's satisfaction.

Concurrent engineering, customers and suppliers' involvement, visual management, group work and cross-functional teams emerge as some of the techniques used to reach the purpose of LPD (Karlsson \& Ålhström, 1996). Standardizing the PD process, reducing the size of batches transmitted from one stage to another and a strong project leader who represents the customer and is capable of crystallizing his or her team members' capacities are all factors that make the stream of the process flow faster (Kristofersson \& Lindeberg, 2006).

LPD is based on continuous improvement, and its implementation takes time and requires humility and commitment to enable improvement in a company. Tools adapted from Lean Manufacturing e.g. 5S, Kaizen (Womack, Jones \& Roos, 1991), process mapping, quality tools etc., can be used as soon as they are made to fit PD (e.g. 5S would focus more on the elimination of unwanted information that on cleaning the manufacturing environment). In addition, tools that help the visualization of a project and the communication inside the project team can be used to help the team members to know their role. In this way, they will feel more involved in the project (e.g. a dedicated room for each project, list of tasks that need to be done and prioritized, or a project chart at the beginning of the project, Liker \& Morgan, 2006, Reinertsen, 2005).

Finally, LPD does not propose a roadmap for PD but is an initiative that helps to improve and standardize the existing process in a company.

\section{Design for Six Sigma}

DFSS is a structured methodology for PD that consist of a stage gate model, with deliverables and norms of robustness that must be approved at the end of each stage, before a project proceeds forward (Tennant, 2002). With this methodology, a company 
is supposed to be able to turn its PD into customer satisfaction measurable factors (Tennant, 2002). Gremyr (2005) defined it as follows:

\footnotetext{
"Design for Six Sigma is a means of developing, or improving, products that enables Six Sigma levels of performance in production, while focusing on customer satisfaction and robustness. An outcome of Design for Six Sigma is that the product can be produced at predictable levels of costs and risks"
}

According to Cronemyr (2006), every company adapts DFSS for its own needs, which make its process different from one company to another. One roadmap seems to be common to some industries: Define, Measure, Analyze, Design and Verify $(D M A D V)$. Each step is a memo for the project team members: a way to split PD into different phases and to keep in mind the important phases of a development project. These phases enable a team to focus on each separate step of the process, to reduce the risks of going too fast during one phase, and to define deadlines for every team member (Harry \& Schroeder, 2000).

DFSS proposes a set of tools and techniques that is fit to PD and that can be used during the different steps (Cronemyr, 2006). Some of them are taken from Six Sigma, which facilitates the implementation of DFSS in companies already using Six Sigma. Quality and customer requirements are the heart of the methodology.

Innovation is controlled and needs to show its robustness for customer satisfaction (Tennant, 2002). It seems to be reduced by administrative tasks (e.g. checklists to be filled in etc.) and every innovation has a level of robustness that must be attained that is fixed by customers' expectations (Tennant, 2002). DFSS requires cross-functional teams (Chowdhury, 2002), where interaction between people can bring innovation.

DFSS turns the process of PD from deterministic to probabilistic by giving to the PD team the opportunity to use statistical tools, e.g. Design of Experiment (Creveling, Slutsky \& Antis, 2003). Finally, DFSS integrates the Six Sigma hierarchy, and its projects are generally assisted by 'Black Belts' educated in DFSS (Tennant, 2002).

\section{Analysis}

In this section, DFSS and LPD are compared by themes in the selected literature and practical insight is given derived from the practitioners' interviews.

\section{Enabling DFSS and LPD in a Company}

\section{Philosophy}

LPD is founded on developing quality products by continuously improving PD and creating a flow of value added activities (Reinertsen, 2005). DFSS seems to be centered more on measurements of customer satisfaction and the robustness of the product (Tennant, 2002). The methodologies are linked by the fact that they emphasize effort at the beginning of projects in order to reduce later rework.

\section{Strategy}

The Lean and DFSS methodologies have different effects on the strategy of the company. DFSS gives a robust output, followed by a complete documentation: the idea is to promote the company as a leader in quality (Tennant, 2002). The strategy behind LPD is a strong reactivity to market demands and positioning the company as a quality leader (Liker \& Morgan, 2006, Reinertsen, 2005 etc).

Implementation

DFSS and LPD differ from an implementation point of view. Where DFSS seems to be possible to integrate quickly in some companies (e.g. two years for VCC, already used working with Six Sigma methodologies), LPD's implementation never seems to end 
(Karlsson \& Ålhström, 1996). However, both methodologies’ implementation makes companies centre around the demand for knowledge (Harry \& Schroeder, 2000, Liker $\&$ Morgan, 2006). People need to want change and improvement and to learn by means of the way they do things; otherwise, their application will not create value.

\section{Process and Communication}

DFSS and LPD emphasize group work to facilitate communication in PD teams (Chowdhury, 2002, Liker \& Morgan, 2006). LPD does not use any standardized process whereas DFSS uses standard roadmaps that guide project leaders, e.g. DMADV (Gremyr, 2005, Womack \& Jones, 1996). According to practitioners (VCC, GE, Volvo Aero), this latter methodology has a slower process and increases administrative tasks in order to protect the PD process against unwanted variation (Tennant, 2002). LPD seems to be used to improve the former PD process or to try to standardize the way of doing things in the company (Womack \& Jones, 1996), whereas DFSS seems to take the place of the former way of doing things at some of the interviewed company (VCC, GE).

Communication is eased in both methodologies for different reasons: reduction of batch sizes, process mapping etc., in the case of LPD (Liker \& Morgan, 2006) and process mapping, stage gate models etc., in the case of DFSS (Creveling, Slutsky \& Antis, 2003). There is also a difference between the size of the batches of information in the two methodologies. LPD seems to have as a principle to reduce those batches in order to give greater flow to the process (Reinertsen, 2005) while DFSS requires for robust and documented deliverables.

Finally, practitioners and reports in the literature, such as Liker \& Morgan (2006), Clausing (1994), Tennant (2002), agree that putting more effort at the beginning of PD will make it faster and more efficient at the end, and both methodologies use this assumption to emphasize the first important actions to take: understanding the customers and writing a detailed project chart.

\section{Uses of DFSS and LPD}

Management and Teams

LPD and DFSS have two management styles. First, they are methodologies that help project leaders to accomplish their tasks of developing, but offer no training on management skills to a project leader. Nevertheless, some tools exist, e.g. process mapping (Creveling, Slutsky \& Antis, 2003, Reinertsen, 2005), explicitly to support project leaders. DFSS seems to be there to help leaders to be more secure about the outputs of their projects (VCC, Volvo Aero and GE), whereas LPD is supposed to enable management to see the faults in their PD process and give them the opportunity to improve it.

Secondly, LPD and DFSS use cross-functional teams, trying to integrate people from different departments in the projects in order to create interaction between them and to give to the project the insights of their functional organization's requirements. This will increase the efficiency of the later phases of development (Liker \& Morgan, 2006, Tennant, 2002). LPD and DFSS differ in their ways of empowering top management. DFSS uses the stage gate model, which gives managers an opportunity to request changes during the project, while LPD has no model that includes specific stages (Karlsson \& Ålhström, 1996): it is thus harder for management to get involved. Some managers (Bahco, Scania, and Autoliv) nevertheless said that visual management enabled them to be regularly updated about the advancement of PD projects.

\section{Organization}

In a DFSS project, everyone knows what to do and what deliverables are expected. A parallel hierarchy is also needed with the "belt hierarchy" (Bergman, Kroslid \& Magnusson, 2003). LPD concentrates the efforts on continuously improving the PD 
organization, on showing the opportunities for modifying the organization and on giving deadlines to project workers (defined e.g. during the process mapping, Reinertsen, 2005). Both methodologies' projects are held by project owners. In DFSS, the project leader can be outside the belt hierarchy if a tier's process helps the team to follow the methodology (e.g. at VCC) or if everyone before has received training in Six Sigma and DFSS, as is the case at GE. They are both demanding cross-functional interactions. DFSS gives a structure and a clear picture of the work approach through its roadmap (e.g. DMADV) whereas this vision can be blocked with LPD.

Tools

There are no rules for tools to be used in the two methodologies. DFSS uses a stage gate model in which tools known from the quality and robustness areas fit to PD (Creveling, Slutsky \& Antis, 2003, Wilson, 2005 etc). However, e.g. VCC gives the freedom to project leaders to choose the tools they think the team needs. LPD does not give a toolbox, even though the same tools are used by most of the interviewed practitioners because they answer to the needs of communication and visualization of the projects, e.g. process mapping. The tools should also correspond to the team demands for continuous improvement (Reinertsen, 2005).

\section{Innovation and Creativity}

Even though some authors (Chowdhury, 2002, Tennant, 2002 etc.) and some of the practitioners interviewed (e.g. at Volvo Aero) argue that innovation tools fit the structure of DFSS and that innovation is only limited by the robustness and quality requirements, it is possible to assume that innovation will depend on the company and the way it uses DFSS. LPD integrates innovation depending on the company: order in PD is good for innovation according to the LPD practitioners interviewed since it will come from the interaction of specialists. DFSS has an innovation toolbox, with tools like TRIZ, brainstorming sessions etc. (Creveling, Slutsky \& Antis, 2003), whereas LPD project innovation does not necessarily come from the methodology itself but from the flexibility it provides (Liker \& Morgan, 2006, Reinertsen, 2005).

\section{Dealing with External Factors}

\section{Customers and Suppliers}

LPD and DFSS are two methodologies driven by and towards customers' satisfaction (Chowdhury, 2002, Karlsson \& Ålhström, 1996). In this area, both methodologies apply the same quality tools, e.g. Quality Function Deployment. The team members are asked to keep customers in mind throughout a project. In LPD, team leaders usually represent the voice of the customer in the project team, which thus gives customers a representative throughout the project (Liker \& Morgan, 2006). This has to be taken delicately, because it could be restrictive if the project team relies only on this person. LPD and DFSS also give tips to help the teams to understand their customers. Visiting the customers' life area is one of them: all the developers should go there in order to understand what kind of product the customers would ask for and how they would use it (Tennant, 2002). Finally, LDP sometimes includes suppliers in the process (Karlsson \& Ålhström, 1996). Practitioners that do this (Bahco, Scania) seem to have positive returns. DFSS does not always include them but, to evaluate what capability it is possible to achieve, it is strategic to know what suppliers' capabilities are. Hence, according to some practitioners, some work needs to be done with them (VCC, Volvo Aero, and GE).

\section{Expected Results of the Methodologies}

DFSS and LPD have two distinctive ways of attaining their goal. The first gives a standardized structure (Cronemyr, 2006). The second seems to enable the creation of a standard by making the problems - and their solutions - in PD apparent (Reinertsen, 2005). This makes possible an improvement and its standardization. In practice, both 
methodologies also seem to have results that are indirect consequences of their application. The first one is the commitment of team members. Driven by a charismatic leader, by the vision they may have of the project or by the definition of their role in the team with deliverables and deadlines, all the team members can feel their responsibilities (Tennant, 2002, Liker \& Morgan, 2006). Bahco for example even has employees that are disappointed not to be more involved in some projects according to the definition of their roles. The second result is a healthy pressure put on employees, who know what needs to be done and when. A pulse meeting can be held every week in LPD projects, and deadlines for DFSS projects put the necessary pressure on the employees, hopefully without being either inhibitory, or overwhelming.

Lastly, both methodologies increase the demand for knowledge in the groups (Liker \& Morgan, 2006, Tennant, 2002). DFSS helps VCC teams to know more about their product, LPD helps Scania, Autoliv and Bahco to know more about their processes, and both methodologies, as described in the literature (Mascitelli, 2004, Wilson, 2005, Cronemyr, 2006 and Creveling \& Slutsky \& Antis, 2003), should help the companies to know more about their customers. This last point has nevertheless not been verified in all of the companies.

Table 1 summarizes the synergies and the differences (given as an attachment). The synergies are listed in one column and the differences specific to either DFSS or LPD are given in separate columns.

Some major factors have been extracted from the table of comparisons and sorted into three different themes, Principles, Practices and Tools (Table 2), as described by Dean \& Bowen (1994). These factors are named in the literature and mentioned in the interviews. It is agreed that more factors can be added in further studies, and the list is not exhaustive. This table nevertheless gives a summary of some of the findings of the study.

\begin{tabular}{|c|c|c|c|c|c|}
\hline & & $\begin{array}{l}\text { Literature } \\
\text { DFSS }\end{array}$ & $\begin{array}{l}\text { Literature } \\
\text { LPD }\end{array}$ & Practitioners DFSS & Practitioners LPD \\
\hline \multirow[t]{8}{*}{ Principles } & Robustness & $\mathrm{X}$ & & $\mathrm{X}$ & \\
\hline & Customer satisfaction & $\mathrm{X}$ & $\mathrm{X}$ & $\mathrm{X}$ & $\mathrm{X}$ \\
\hline & Structured & $\mathrm{X}$ & & $\mathrm{X}$ & \\
\hline & Flow product development & & $\mathrm{X}$ & & $\mathrm{X}$ \\
\hline & Product portfolio & & $\mathrm{X}$ & & $\mathrm{X}$ \\
\hline & Standardizing by improving what & & & & \\
\hline & exists & & $\mathrm{X}$ & & $\mathrm{X}$ \\
\hline & Quality & $\mathrm{X}$ & $\mathrm{X}$ & $\mathrm{X}$ & $\mathrm{X}$ \\
\hline \multirow[t]{9}{*}{ Practices } & Structure & $\mathrm{X}$ & & $\mathrm{X}$ & \\
\hline & Stage gate model & $\mathrm{X}$ & & $\mathrm{X}$ & $\mathrm{X}$ \\
\hline & Statistic oriented & $\mathrm{X}$ & & $\mathrm{X}$ & \\
\hline & Reducing unwanted variation & $\mathrm{X}$ & $\mathrm{X}$ & $\mathrm{X}$ & $\mathrm{X}$ \\
\hline & Continuous improvement & & $\mathrm{X}$ & $\mathrm{X}$ & $\mathrm{X}$ \\
\hline & Visual management & & $\mathrm{X}$ & & $\mathrm{X}$ \\
\hline & Prioritization & & $\mathrm{X}$ & & $\mathrm{X}$ \\
\hline & Making errors appear & & $\mathrm{X}$ & & $\mathrm{X}$ \\
\hline & Reduction of waste & $\mathrm{X}$ & $\mathrm{X}$ & & $\mathrm{X}$ \\
\hline \multirow[t]{6}{*}{ Tools } & Robust Design Methodologies & $\mathrm{X}$ & & $\mathrm{X}$ & \\
\hline & FMEA & $\mathrm{X}$ & $\mathrm{X}$ & $\mathrm{X}$ & $\mathrm{X}$ \\
\hline & QFD & $\mathrm{X}$ & $\mathrm{X}$ & $X$ & \\
\hline & Pugh & $\mathrm{X}$ & & $\mathrm{X}$ & \\
\hline & $5 \mathrm{~S}$ & $\mathrm{X}$ & $\mathrm{X}$ & & $\mathrm{X}$ \\
\hline & Kaizen & & $\mathrm{X}$ & & $\mathrm{X}$ \\
\hline
\end{tabular}

Table 2 Principles, Practices and Tools

The contents of this table is organized and summarized in Figure 1 below. This picture tries to summarize the principles, the practices and the tools of both methodologies, placing each in parallel. The darkness of one area indicates the emphasis of the 
methodology, in a PD project: the justification for the importance of the methodology in the area by means of identified factors is given to the side.

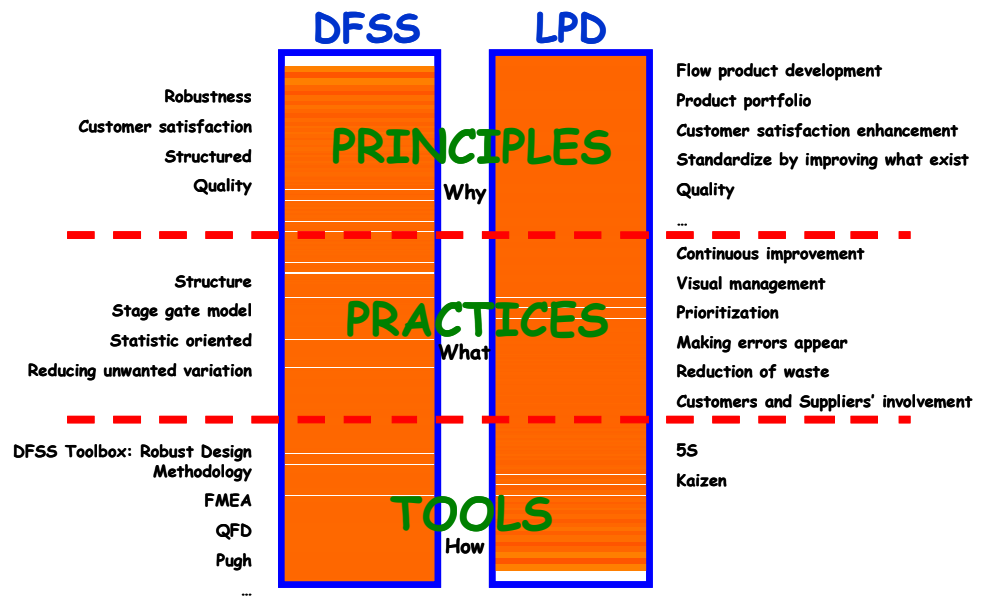

Figure 1 Comparison of the principles, the practices and the tools of DFSS \& LPD

\section{Discussion and Conclusions}

This paper gives a comparison of DFSS and LPD that attempts to highlight the differences, links between and synergies of the two methodologies. Input from practitioners and from the literature gives a broad understanding of the methodologies and an insight into the way in which they can be implemented. Finally, the study offers a comparison of the two methodologies, and a table that summarizes the findings. The comparison and the descriptions of LPD and DFSS allow some conclusions about their differences, links and synergies.

The first synergy is the call to put the effort at the front of PD. Both methodologies say that the more a team reflects at the beginning of the project, the faster it will go at the end. Enhancing quality, visiting and understanding customers etc., are all signs of synergies of the methodologies. In addition, the commitment of the team members to the methodology, the importance of cross-functional teams and of the project owners and the importance of the definition of customers seem to show strong similarities in the LPD and DFSS methodologies.

Links can be found between DFSS and LPD. Indeed, the ability of LPD to make PD go faster and the structure of DFSS and the robustness of its output that comes from its probabilistic tools may give a hint to practitioners that they can take parts from one of them in order to improve the other. Visual management of LPD can be linked to the name of DFSS's roadmaps because they give everyone in the project an idea of how much the development has advanced.

Finally, the principal differences found between LPD and DFSS have to do with their processes and their philosophies. DFSS uses a standardized process in which the philosophy is to measure and attain customer satisfaction, while LPD helps to standardize the existing process by continuously improving it, so that its philosophy would be to be open to changes in product development, with always being able to call the process in question. Another difference has to do with the toolboxes. While both seem to be helped by the use of quality tools, DFSS has a toolbox with probabilistic methods, while LPD lets the company use what they know, or need, to improve their quality. A final important difference has to do with the batch sizes delivered to the next level in PD: the reduction of batch sizes that LPD aims at can be in contradiction to the detailed deliverables DFSS looks for. 
These findings have come from a limited number of interviews and reports in the literature and can thus not be generalized. Still, the particular characteristics of one company can sometimes enlighten other companies. In addition, the conclusions will hopefully give practitioners and scholars ideas about why they should or why they should not find a "hybrid" methodology that merges the strengths of DFSS and LPD.

\section{References}

Bryman, Alan, 2004, Social Research Methods, Second Edition Oxford.

Bergman, Bo, Kroslid, Dag, Magnusson, Kjell, 2003, Six Sigma, The Pragmatic Approach, Second Edition, Studentlitteratur, Sweden.

Brown, Shona L., Eisenhardt M., 1995, Product Development: Past Research, Present Findings, And Future Directions, The Academic Management Review, Vol.20, No.2, pp 343-375.

Clausing, Don, 1994, Total Quality Development, A Step by Step Guide to World-Class Concurrent Engineering, ASME Press. New York.

Chowdhury, Subir, 2002, The Power of Design for Six Sigma, Dearborn Trade, Chicago.

Creveling, C. M., Slutsky, J.L., Antis, D. jr, 2003, Design for Six Sigma in Technology and Product Development, What to Do \& When to Do It, Prentice Hall PTR, New Jersey

Cronemyr, Peter, 2006, DMAIC DMADV, Differences, Similarities and Synergies.

Dean, James W., Bowen, David E., 1994, Management Theory and Total Quality: Improving Research and Practice through Theory Development, The Academic Review, vol.19, No.3, Special Issue: Total Quality, pp. 392-418.

Gremyr, I., 2005, Exploring Design for Six Sigma From the Viewpoint of Robust Design Methodology, Journal of Six Sigma and Competitive Advantage, Vol. 1, No.3, pp 295-305.

Harry, Mikel, Schroeder, Richard, 2000, Six Sigma, the Breakthrough, Management, Strategy, Revolutionizing the World's Top Corporation, Currency, New York.

Karlsson, Christer, Ålhström, Pär, 1996, The Difficult Path to Lean Product Development, Journal of Product Innovation Management, 13, pp 283-295.

Kristofferson, A., Lindeberg, C., 2006, Lean Product Development in Swedish Industry, Master's Thesis, Stockholm School of Economics.

Mascitelli, Ron, 2004, The Lean Design Guidebook - Everything Your Product Development Team Needs to Slash Manufacturing Costs, Technology Perspectives, Northridge.

Mehri, Darius, 2005, The Darker Side of Lean, an Insider's Perspective on the Realities of the Toyota Production System, Cornell University Press.

Morgan, James M., Liker, Jeffrey K, The Toyota Product Development System, Integrating People, Process, and Technology, Productivity Press 2007, New York.

Productivity Press Development Team, 2005, Lean Supply Chain: Collected Practices

\& Cases, Productivity Press,

Reinertsen, Donald, 2005, Let It Flow, Industrial Engineering, pp41-45.

Reinertsen, Donald, 2005, How Lean Product Development Sparked a Revolution, Institute of Industrial Engineers.

Sethi, Rajesh, 2000, New Product Quality and Product Development Teams, Journal of Marketing, , Vol. 64, p2.

Schein, E., 1992, Organisational Culture and Leadership, Jossey-Bass, San Francisco. Tennant, G., 2002, Design For Six Sigma, Launching Products and Services without Failure, Gower, Hampshire. 
Urban, G.L., Hauser, J.R.,1993, Design and Marketing of New Product, Prentice Hall, New Jersey.

Wilson, G., 2005,Six Sigma, and the Product Development Cycle, Oxford, Oxford. Womack, J.P., Jones, D.T., Roos, D., 1991, The Machine that Changed the World, Rawson Associates, New York. 


\begin{tabular}{|c|c|c|c|}
\hline & synergies & DFSS & LPD \\
\hline \multirow[t]{4}{*}{ Expected results } & - 'T op class' Q uality & - R obust design & - Fast flow \\
\hline & - Understanding of customers & - R esults ifficult to perceive & - Q uality \\
\hline & - Commitment of project team members & - Q uality & - $\vee$ isual management $\rightarrow 0$ pportunity to correct errors \\
\hline & - $\mathrm{H}$ ealthy pressure & - Knowledge about product & - Standardize product development process \\
\hline \multirow[t]{3}{*}{ New technologies } & - $\mathrm{N}$ eed to show value added on product & - Independent from new technologies & - Adaptation to needs of product development \\
\hline & - R obustness of technology once implemented & - $\mathrm{H}$ ave to bring knowledge & - For people not instead of people \\
\hline & - Increase the knowledge of companies & & \\
\hline \multirow{2}{*}{$\begin{array}{l}\text { Customers \& } \\
\text { Suppliers }\end{array}$} & - Integration of next people working in the process & - $\mathrm{N}$ o help to work with suppliers & - Project leader represent V oice of C ustomer \\
\hline & - Customer visit: gemba & & - W orking sessions with suppliers: part of the team \\
\hline \multirow[t]{4}{*}{ Tools } & - Q uality tools & - Stage gate model & - No toolbox \\
\hline & - Customer focus tools & - Standardized & - Adapted tools \\
\hline & - T ools do not give solutions & - Q uality and robust tools & $.5 \mathrm{~S}$ \\
\hline & & - T ool box & \\
\hline \multirow{3}{*}{ Organization } & - Personal tasks, goals and dead lines known & - Clear process for everyone & - 0 ne project one room \\
\hline & - Project owner & - D ead lines & - Flow \\
\hline & & & - Concurrent engineering \\
\hline \multirow{4}{*}{$\begin{array}{l}\text { Management \& } \\
\text { Teams }\end{array}$} & - N o management tools & - Deliverables for everyone & - $V$ isual $M$ anagement \\
\hline & - Cross-functional teams & - T eam leader more secured & - Cross functional teams \\
\hline & - T aking care of harmony of the project with the other & - Cross-functional teams & - Leader implicated and capable, sometimes mostly \\
\hline & departments & - Stage gate model & administrative \\
\hline \multirow{5}{*}{$\begin{array}{l}\text { Process \& } \\
\text { Communication }\end{array}$} & - efforts at the beginning & - Stage gates model & - Based on the previous process \\
\hline & - group work and brainstorming & - Increase administrative work & - Parallel work: concurrent engineering \\
\hline & - Process mapping & - Process mapping and responsibilities & - $\mathrm{V}$ isual communication, visual processes \\
\hline & - Project chart & - Structured & - N o process defined \\
\hline & & - D etailed batches of information & - Small batches of information \\
\hline \multirow[t]{3}{*}{ Implementation } & - Becoming a company promoting knowledge & - Change in culture & - T akes time: continuous improvement \\
\hline & - Culture of change & - Breakthrough & - Standardizing little by little \\
\hline & & - After / Same time/ before Six Sigma? & - H umility for everyone: ability to accept mistakes \\
\hline \multirow{2}{*}{ Strategy } & - Thorough study of competitors & - T horough study of competitors & - D evelopment of Portfolio thanks to Just In T ime \\
\hline & - D efinition of targeted customers & - D efinition of targeted customers & - D efinition of targeted customers \\
\hline \multirow[t]{2}{*}{ Philosphy } & - Product development learned through improvment & - M ethodology driven & - Improvement driven \\
\hline & - Q uality from the start & - Probabilisty \& M easurment & \\
\hline
\end{tabular}

Table 1 Comparison of the methogologies 